\title{
EL LICENCIADO VIDRIERA Y DON QUIJOTE
}

Hasta el momento en que J. B. Avalle-Arce escribió una introducción al Licenciado Vidriera comparando los personajes del licenciado Vidriera y don Quijote, sólo unas escuetas referencias se habían escrito mencionando el parecido entre ambos personajes. Y en la mayoría de los casos se había evitado cualquier conclusión o estudio pormenorizado de las semejanzas.

En 1901, Julián Apraiz hizo una brevísima referencia a una señora Chesner, quien concibió el Licenciado Vidriera como germen del Quijote (p. 70) '. Alonso Cortés mencionó el parecido en su edición del Licenciado Vidriera, publicada en 1916 (Prólogo, pp. XLV-XLVI) ${ }^{2}$. Entwistle en un trabajo original de 1940, tan polémico como sugestivo, afirmó que el Licenciado Vidriera es un boceto del Quijote, evitando cualquier estudio (pp. 101-107) ${ }^{3}$. González de Amezúa cita a Gianinni, para quien el Licenciado Vidriera es un hermano menor de don Quijote; añade que si la aparición de éste no fuese anterior a las Novelas Ejemplares, sentiría la tentación de ver en esta novela un esbozo del generoso héroe de la Mancha (II, p. 174) 4. Otros autores más recientes, casos de José Manuel Udina y Fernando de Toro, mencionan que existe una semejanza entre ambos personajes, pero sin entrar en otros pormenores s. Avalle-Arce, finalmente, en su edición publicada

1 Julián APRaIz, Estudio histórico-crítico sobre "Las Novelas Ejemplares" de Cervantes. Vitoria, 1901. 1916.

2 N. Alonso Cortés, El Licenciado Vidriera. Valladolid, Imprenta Castellana,

${ }^{3}$ Willum J. Entwistle, Cervantes. Oxford, 1965 (1940).

4 A. Gonzallez de AmezúA, Cervantes creador de la novela corta española Madrid, CSIC, 1958, 2 vols.

5 Miguel de Cervantes, Novelas Ejemplares. Barcelona, Carroggio Ediciones, 1977. Estudio preliminar de José Manuel Udina. Miguel DE CervanTes, El Licenciado Vidriera Madrid, SGEL, 1976. Adaptación de Fernando de Toro Garland. 
en 1982, comenta las afinidades entre ambos personajes. Destaca el mencionado profesor que ambos personajes son locos intelectuales: «la locura, como solidaria del intelecton; la polionomasia y la anonimia: ambos personajes adquieren varios y distintos nombres, y omiten el nombre de sus padres y respectivas patrias; y poseen en común la amalgama de Armas y Letras, que es la que cimenta el sentido íntimo de la vida de ambos protagonistas (II, Introducción, pp. 16-25) ${ }^{6}$.

No descarto que algún otro comentario se haya podido escapar a mi lectura. Pero tampoco demasiado importante.

Avalle-Arce piensa que la novelita fue compuesta entre las dos partes del Quijote: "No olvidemos que esta última novela (el $L i$ cenciado Vidriera) se compone entre las dos partes del Quijoten (p. 17), y no ofrece ninguna conclusión.

En este artículo pretendo demostrar que el parecido entre ambos personajes es claro, como evidente es que el personaje de don Quijote es superior, literariamente hablando. A partir de aquí, creo que es más lógico pensar en una evolución artística de Cervantes, quien llegaría a don Quijote a partir del licenciado Vidriera, que no en una involución. Las referencias cronológicas en la novelita a la Corte de Valladolid no debe suponer ningún obstáculo, pues así como tenemos dos versiones de Rinconete $y$ Cortadillo y El celoso extremeño, sabemos que el Persiles tuvo varias fases de redacción ?. No debe extrañar, por otra parte, que un escritor trabaje en varias obras, tomando y dejándolas indistintamente. Cervantes debió concebir al licenciado Vidriera antes que a don Quijote; debió abandonarlo por el feliz hallazgo del Entremés de los Romances, y actualizó la historia con los libros de caballerías. Después continuaría la novela del Licenciado Vidriera para hacerla formar parte del volumen de doce con las cuales noveló por primera vez en lengua castellana.

Pero vayamos por partes. Primero hemos de aceptar que el parecido entre ambos personajes existe.

6 J. B. Avalle ARCE, Novelas Ejemplares. Madrid, Castalia, 1982, 3 vols.

7 J. B. Avalle Arce, Los trabajos de Persiles y Sigismunda Madrid, Castalia, 1969. Rafael Osuna, «El olvido del Persiles, en Boletín de la Real Academia Española, XLVIII, 1968. RAFAEL LAPESA, "En torno a La española inglesa y el Persiles, en Homenaje a Cervantes. Valencia, 1950, II, ed. Sánchez Castañer, pp. 367-388. 


\section{LA LOCURA}

En la obra de Cervantes existen personajes que padecen algún trastorno mental: Cardenio, por ejemplo; o se narran cuentos de locos: Don Quijote, II, 1. Pero sólo en la novela del Licenciado Vidriera y en Don Quijote son los personajes dementes los protagonistas de la obra.

Además, los síntomas que padecen ambos son muy semejantes: se quedan en los huesos y muestran tener turbados los sentidos (II, p. 117) (Don Quijote, I, 1, pp. 35-36).

El uno y el otro hablan concertada y elegantemente, pareciendo personas juiciosas; pero sus conductas son disparatadas o anormales (p. 142) (DQ, II, 17, p. 705).

Tienen tendencia a las voces y a los escándalos. Así como a que los muchachos les acompañen: el licenciado Vidriera vocea para que nadie se le acerque y le quiebre (p. 117); don Quijote acaba con el retablo de Maese Pedro ( $D Q$, II, 26, pp. 778 y ss.). Al primero le siguen los muchachos (p. 118); al segundo, en Barcelona, también (DQ, II, 62, p. 1056).

En sus nuevos estados mentales, los dos cambian de vestuario: el uno para no quebrarse, y el otro para ser un caballero andante (pp. 117-118) (DQ, I, 1, pp. 36-38).

Los amigos del licenciado y de don Quijote les encierran a causa de sus locuras: "Tuviéronle encerrado sus amigos mucho tiempo; pero viendo que su desgracia pasaba adelante, determinaron de condescender..." (p. 118) ${ }^{\text {8; }}$ Don Quijote inicia su primera salida por la puerta de atrás de su casa (I, 2, p. 40); hacen de su biblioteca una hoguera en el famoso escrutinio (I, 6, pp. 69 y ss.); el cura y el barbero tratan de rescatar a don Quijote de Sierra Morena (I, 27, pp. 281); o regresa a la aldea enjaulado (I, 47, pp. 510 y ss.).

Ambos son tildados de "pobres" por el narrador en un tono compasivo: "...lo que se granjeaba en esto era que el pobre se echaba en el suelo dando mil gritos..." (p. 117); "Imaginábase el pobre ya coronado por el valor de su brazo..." (I, 1, p. 36).

Los dos personajes tienen una dieta estrecha (p. 142) (I, 1, pp. 32-33).

${ }^{8}$ Para el Licenciado Vidriera he seguido la edición de AvAlLE-ARCE, Novelas Ejemplares. Madrid, Castalia, 1982, 3 vols. El volumen II incluye el estudio preliminar y el texto del Licenciado Vidriera.

Para Don Quijote de la Mancha, MARTIN DE RIQUeR, Don Quijote de la Mancha Barcelona, Planeta, 1980. 


\section{POLIONOMASIA}

Tomás Rodaja se convierte en el licenciado Vidriera a causa de un membrillo que le ofreció una dama «de todo rumbo y manejow. Recuperada la cordura será el licenciado Rueda.

El hidalgo Quijada o Quesada o Quejana, a fuerza de leer libros de caballerías, decide armarse caballero andante, y toma el nombre de don Quijote de la Mancha. En el transcurso de sus aventuras se llamará el Caballero de la Triste Figura, el Caballero de los Leones, el pastor Quijotiz, etc... Al recobrar el juicio, como el licenciado Vidriera, cambiará de nombre: será Alonso Quijano el Bueno.

La mujer de Sancho también tendrá varios nombres: Juana Gutiérrez, Mari Gutiérrez, Juana Panza, Teresa Cascajo o Teresa Panza. El bachiller Sansón Carrasco se convertirá en el Caballero del Bosque, y en el Caballero de la Blanca Luna. Monipodio modificará los nombres de Rincón y Cortado en Rinconete y Cortadillo. Cervantes utilizará el recurso del apodo en La Gitanilla, con el personaje de Preciosa, etc...

En los casos del Licenciado Vidriera y de Don Quijote, la polionomasia responde a un sentido existencial: los dos personajes asumen nombres diferentes según los distintos momentos por los que atraviesan sus vidas. Esta es la diferencia sustancial con respecto a los otros ejemplos.

\section{AUTOBIOGRAFISMO}

Volveré a recordar las palabras de Avalle-Arce, quien señaló que la amalgama de Armas y Letras es la que cimenta el sentido intimo de las vidas de los protagonistas. De idéntico modo que a Cervantes: recordemos la batalla de Lepanto y su obra literaria.

La producción literaria de cualquier autor parte de la experiencia del creador. Y Cervantes no es una excepción. En el conjunto de su obra está presente su cautiverio en Argel.

Aunque otros personajes surgiesen de su experiencia, Rinconete y Cortadillo por ejemplo, el licenciado Vidriera y don Quijote arrancan más hondamente de la conciencia de su creador.

Podríamos establecer las equivalencias de los dos personajes literarios con su creador: son excelentes lectores; no están determinados por los padres ni la patria, sino que son hijos de sus propias obras; viven en condiciones económicas apuradas; sus vidas son dinámicas: continuamente se trasladan de un lugar a 
otro; muestran una gran capacidad para el ingenio y la imaginación; se encuentran posicionados frente al mundo que los rodea; viven con inquietud el sentido de la existencia humana, etc...

En definitiva, como muy agudamente apuntó el profesor Avalle-Arce, el sentido íntimo de las vidas de los protagonistas es semejante. Y esta semejanza alcanza también a su creador, Miguel de Cervantes.

\section{SOCIEDAD DE LA ÉPOCA}

Caminando por las calles, el licenciado Vidriera hará uso de su ingenio pasando revista a una buena parte de la sociedad de la época. Una ropera, mujeres amancebadas, un labrador-cristiano viejo, maestros de escuela, alcahuetas, pintores, poetas, un librero, unos azotados, un mozo de mulas, un boticario, los médicos, el juez, el letrado, el mercader, un sastre, zapateros, una tendera, pasteleros, un comediante, escribanos, alguaciles, músicos, religiosos, murmuradores, gariteros y tahúres, etc...

En el Quijote la muestra no es menor y es más rica. En el resto de la obra de Cervantes no hay otro lugar donde la sociedad que le tocó en suerte conocer desfile ante el propio autor primero, y el lector después.

Quisiera haber demostrado hasta este momento que el parecido entre estos dos personajes existe. Ahora mantiene mi curiosidad las diferencias entre ambos.

La diferencia más importante atañe a la locura de ambos personajes. Tomás Rodaja ha visto perturbados sus sentidos a causa de un membrillo, e imagina estar hecho de vidrio. A partir de este momento, expresa su ingenio a través de los famosos aforismos.

Por su parte, don Quijote ha leído con demasiado ímpetu muchos libros de caballerías, lo que ha trastornado su juicio. Su fantasía está llena de aventuras que poblarán la realidad que lo rodea.

Se observa claramente un mayor poderío expresivo en la locura de don Quijote, pues le permite desarrollar una mayor capacidad imaginativa, humorística y literaria. El licenciado Vidriera, sin embargo, se limita a la gracia de sus aforismos y a una crítica social directa.

Podríamos decir que el Licenciado Vidriera sería un Don Quijote, sin su escudero Sancho Panza, y todos los logros alcanzados 
con este hallazgo; y sin la parodia literaria, con todo el humor, la sátira y la ironía a ella adheridas. De esta manera, mientras el Quijote es una obra más literaria que filosófica, aunque con una filosofía, el Licenciado Vidriera resulta más filosófico. El Quijote es superior artísticamente, y está concebido en un estado psicológico superior.

Llegados a este punto, creo que es más lógico pensar en una evolución artística de Cervantes, que no en una involución. El personaje del licenciado Vidriera estaría concebido en la imaginación de Cervantes en un momento anterior a la concepción de don Quijote. No me parece razón suficiente negar esta evolución por razones cronológicas. Cervantes trabajó simultánea e intermitentemente en varias obras ${ }^{9}$. El propio profesor AvalleArce, entre otros críticos, admite que el Persiles tuvo varias fases de redacción. Hasta nuestros días nos han llegado dos versiones de Rinconete y Cortadillo y de El celoso extremeño. Y no de otra manera podríamos explicarnos que entre el inicio del Quijote y su publicación, 1592-1605, transcurriesen trece años.

En conclusión, entre la concepción del personaje del licenciado Vidriera y de don Quijote, interfirió la lectura del Entremés de los Romances ${ }^{10}$, la de multitud de libros de caballerías, y el conocimiento de casos donde la lectura de estos libros produjo alucinaciones ${ }^{11}$.

Hasta aquí lo que podemos saber; luego sobrevendría toda la insondable inspiración de Cervantes.

\section{VÍCTOR EDUARDo MUNGUÍA GARCÍA}

9 Geoffrey StagG, "Castro del Río, ¿cuna del Quijote?», en Clavileño, núm. 36, 1955.

10 G. Stagg, ibid. R. Ment́ndez Pidal, De Cervantes y Lope de Vega. Madrid, Espasa-Calpe, Col. Austral, 1964, 6.' ed. (1940).

$"$ M. Menéndez y Pelayo, "Cultura literaria de Cervantes y elaboración del Quijoten, en Revista de Archivos, Bibliotecas y Museos. Madrid, XII, 1905, p. 334. 